\title{
LOS JUDÍOS DE LA ALMUNIA DE DOÑA GODINA, VILLA ARAGONESA DE SEÑORÍO, EN LA SEGUNDA MITAD DEL SIGLO XV*
}

ENCARNACIÓN MARÍN PADILLA

CSIC. Madrid

\section{Pardo}

El único judío con este apellido que aparece en la documentación consultada para este estudio es Simuel Pardo. Simuel fue amigo del converso Jaime de Urgel, de Ricla, que tuvo casa en La Almunia hacia 1463 o después. En cierta ocasión la mujer de Simuel, de la que se ignora el nombre, estuvo en casa del converso guisando hamin con carne de la carnicería de los cristianos, hamin que Jaime comió pero no en viernes ni sábado ${ }^{786}$. Vivió Simuel en unas casas de la judería que lindaban con las de Juce Frances y con las de Mosse Abenforna en 1483, y con las de éste, con las de Alazar Ferrer y con carrera pública en 1485. Simuel era, además, dueño de un huerto "a la puerta Cabanyas» -que lindaba con el de Tomás Cornell, con el de Fernando del Pozo y con La Acequia del río Jalón-, y de una viña en La Carrera de Cariñena, otra en El Plano y tres en Los Quiñones.

Pese a lo que pudiera parecer a tenor de sus propiedades, Simuel tuvo necesidad de recurrir en varias ocasiones a pedir dinero en comanda a cristianos e, incluso, a moros. El 30 de enero de 1483, Simuel recibió en comanda del escudero y notario Remón López cincuenta sueldos ${ }^{787}$; y el 26 de agosto en Calatayud, ocho florines de

* Continuación de SEF XLIX (1989), 135-152 y 235-305; L (1990), 85-127 y 335371; LI (1991), 51-84

786 Z.AAT., leg. del proceso de Jaime de Urgel, sin catalogar, fols. 13-13v: interrogatorio de Jaime, el 11 de julio de 1489 en Zaragoza.

787 Respondió de ellos Simuel con dos de sus viñas de Los Quiñones, una de ellas comprada al mismo Remón (L.A.APN., Miguel Contín, 1483, fols. 4v-5). El 11 de diciembre de dicho año, Remón canceló la comanda (dicho notario y año, fol. 4v, al margen). 
oro del converso bilbilitano Esperandeo Ram, de los que Simuel se comprometió a devolver dos florines cada cuatro meses, pero si dejaba de pagar alguna tanda, podía "seyer secutado por todo" ${ }^{788}$. El 12 de enero de 1484 en dicha ciudad, Simuel recibió en comanda del mercader bilbilitano Juan Calderón noventa y dos sueldos, junto con Abraham Eli, Junez Mehel y Haya Mehel ${ }^{789}$; y el 22 de junio en La Almunia, ciento cinco sueldos de Calema Cayt, moro de Calatorao ${ }^{790}$. El 3 de octubre de 1485 también en La Almunia, Simuel recibió en comanda del escudero Luis Navarro sesenta sueldos ${ }^{791}$.

Pero Simuel debía, además, cierta cantidad «en un quinyan y juramento" a Salamon Levi, de Épila, que éste intentó cobrar sin resultado en repetidas ocasiones, por lo que decidió recurrir a los adelantados de la aljama de La Almunia para que le obligaran a pagar. Según parece, también éstos dieron largas a la cuestión porque, el 2 de octubre de 1486, en presencia de un notario cristiano y de testigos, Salamon compareció ante Johanan Frances y Sento Amato. Después de explicar todo lo que antecede y referirse al daño que la falta del pago le estaba acarreando, los requirió para que

"como juges et adelantados ... cumpliessen de justicia"

porque, en caso contrario, las expensas, daños y perjuicios por no pagar Simuel recaerían sobre ellos, como adelantados. A ello respondieron Johanan y Sento, sin admitir el requerimiento, que cuando les mostrara el quinyan que a su favor tenía, harían pagar a Simuel según justicia ${ }^{792}$.

Cuatro años después y en la misma villa de Épila, Simuel seguía teniendo deudas. El 12 de diciembre de 1490 en dicha villa, María de Bordalba, viuda del escudero Juan de Abiego, sin revocar procuradores nombró como tales al escudero Miguel Guiralt, de La Almunia, y al botiguero Pedro de Urgel, de Épila, para demandar, recibir y cobrar,

${ }^{788}$ Respondió de ellos Simuel con sus casas (C.APN., Juan Remón, 1483, fols. 273v274). El 17 de diciembre de dicho año, recibió Esperandeo los dos primeros florines de oro y entregó el correspondiente albarán (dicho notario y año, fols. 466-466v).

789 Respondió de ellos Simuel con sus casas (dicho notario, 1484, fols. 27-27v).

790 Respondió de ellos Simuel con tres de sus viñas y con su huerto (L.A.APN., Miguel Contín, 1484, fols. 30-30v).

${ }^{791}$ Respondió de ellos Simuel con sus casas y con su viña de La Carrera de Cariñena (dicho notario, 1485, fol. 78v).

${ }^{792}$ Dicho notario, 1486, fol. 93 . A este requerimiento aludí al referirme a la jurisdicción de la aljama. 
en su nombre, de Simuel los treinta sueldos que le debía y tenía que pagarle por los «dos queros gasconiles» que le vendió ${ }^{793}$.

Simuel Pardo, que fue uno de los asistentes a la reunión de la aljama que tuvo lugar el 3 de mayo de 1483 y a la del 11 de abril de 1486, se convirtió, según confesó al tribunal del Santo Oficio el converso Jaime de Urgel ${ }^{794}$. De su hijo Juce Pardo, que fue jubonero, no he encontrado alusión alguna.

Rabiça, de la

Con este apellido sólo aparecen dos judíos residentes en la villa ${ }^{795}$ en la documentación vista para este estudio: Davit y Jehuda de la Rabiça.

De Davit únicamente se sabe que ejerció en la villa su oficio de sastre y que actuó como testigo instrumental el 18 de noviembre de 1491 y el 19 de julio de 1492. Vivió por tanto los días de la expulsión ${ }^{796}$.

Por lo que se refiere a Jehuda de la Rabiça, cuyo parentesco con Davit se desconoce, había residido con anterioridad en Almonacid de la Sierra y era hermano de Acach de la Rabiça.

En abril de 1480, ambos hermanos se trasladaron de dicho lugar a Calatayud para recibir en comanda trescientos sueldos ${ }^{797}$ del notario bilbilitano Esperandeo López ${ }^{798}$, el día 11. Como de dicha cantidad respondió sólo Acach con sus casas de Almonacid ${ }^{799}$ y con un majuelo ${ }^{800}$, no consta si Jehuda tuvo allí alguna propiedad.

\footnotetext{
793 L.A.APN., Martín Ramo, 1490, fols. 157-157v.

794 Z.AAT., leg. del proceso de Jaime de Urgel, sin catalogar, fols. 13-13v: interrogatorio de Jaime, el 11 de julio de 1489 en Zaragoza; tenga en cuenta el lector la fecha en que lo dijo.

${ }^{795}$ Años antes vivieron en La Almunia Sento de la Rabiça y Juce de la Rabiça. Este último se casó con Soli Gallur, de la familia de los Gallur, de Épila.

796 L.A.APN., Miguel Contín, 1491, fol. 103 y 1492, fol. 81.

797 Que le devolverían en tres tandas cada ocho meses, a partir del 1 de diciembre anterior.

${ }^{798}$ Quien a ruegos de algunas personas y como gracia especial otorgó que, cuando se los pagaran, cancelaría esta comanda y cualquier otra obligación que con él tuvieran (C.APN., Forcén López, 1480, fols. 78v-79).

${ }^{799}$ Que lindaban con las de Osiau Çamora y con carrera pública.

${ }^{800}$ Sito cerca de La Viña del Señor, término del lugar, que lindaba con viña de Acach Frances, con la de Abraham Alazar y con El Barranco.
} 
Ignoro cuándo cambió Jehuda su residencia a La Almunia, para vivir en unas casas de la judería que en 1491 lindaban con las de Cidiella Anuadaya, viuda de Salamon Almalcani, y de su hijo Jehuda Almalcani ${ }^{801}$. Jehuda de la Rabiça murió entre octubre de 1491 y julio de 1492, porque cuando se alude a sus casas en este último año, aparece como difunto ${ }^{802}$.

\section{Saltiel}

Son cuatro los judíos con este apellido que aparecen, residiendo en la villa, en la documentación consultada para este estudio: Acach, Mosse, Sento y el sastre Simuel Saltiel; de los dos últimos sólo consta que vivieron allí. La familia judía de los Saltiel tuvo lazos de parentesco con la del converso Jaime de Urgel ${ }^{803}$, que se casó con Juana de Villarroya.

Hacia 1472 Rahel y su marido, uno de los Saltiel, enviaron un plato de turrado judaico a casa de Jaime, pero cuando después mandaron más no lo quiso tomar ${ }^{804}$. Fue por entonces cuando el matrimonio judío invitó a su casa a Juan y Jaime de Urgel, y a sus mujeres, para tomar una colación de avellanas y vino que Saltiel había comprado previamente en la cristiandad ${ }^{805}$. Según Jaime, cuando Saltiel y su hijo, pellicero, le presentaron pan cotazo y turrado, que él y su mujer Juana comieron, en "remuneracion» les envió pan leudo, lechugas y huevos ${ }^{806}$.

Es posible que Rahel fuera la judía que, según se decía, iba en

${ }^{801}$ L.A.APN., Miguel Contín, 1491, fol. 81v.

${ }^{802}$ Dicho notario, 1492, fol. 86.

${ }^{803}$ Esta familia pudo tomar su nombre de Jaime de Urgel, a quien el rey don Martín designó gobernador general suyo y que tuvo su sede permanente en la villa de La Almunia.

${ }^{804} \mathrm{Si}$ algunos testigos perjudicaron a Jaime con sus testificaciones, no ocurrió lo mismo con Rahel, según deja bien claro su testificación. Su marido no compareció ante el tribunal del Santo Oficio.

${ }^{805}$ Z.AAT., leg. del proceso de Jaime de Urgel, sin catalogar, fols. 5-5v: Rahel, el 2 de junio de 1487.

806 Jaime reconoció también que algunas veces comió en La Almunia pan cotazo, "arruquaques" y turrado de los judíos en las "ochavas" de sus pascuas (dicho leg., fol. 4v: Jaime, el 7 de julio de 1488, fol. 14: Jaime, el 11 de julio de 1489 en Zaragoza, y fol. 16: Jaime, el 16 de octubre de dicho año en la misma ciudad). 
algunas fiestas de judíos, a Ricla, a casa de Jaime. Allí comía y bebía y cuando se marchaba, Juana le daba muchas cosas ${ }^{807}$.

En el caso de que el marido de Rahel fuera Acach Saltiel ${ }^{808}$, el pellicero Mosse era hijo del matrimonio.

Acach, que actuó como testigo instrumental el 12 de enero de 1484 en Calatayud y el 28 de septiembre del mismo año en La Almunia ${ }^{809}$, fue dueño de una viña en El Romeral ${ }^{810} \mathrm{y}$, junto con Mosse, asistió a las reuniones de la aljama que tuvieron lugar el 3 de mayo de 1483 y el 11 de abril de 1486 , como se ha visto.

En cuanto a Mosse, se sabe que vivió en unas casas de la judería que en 1492 lindaban con las de Aljohar Cohen —que, a su vez, lo hacían con las de Jaime de Urgel ${ }^{811}-$, y que fue dueño de un majuelo que se encontraba en el mismo término en el que Acach tuvo su viña ${ }^{812}$.

Mosse Saltiel que actuó como testigo instrumental el 21 de febrero de $1492{ }^{813}$, ejercía su oficio de pellejero en la villa cuando se promulgó el edicto de expulsión.

\section{Samarel}

Son tres los judíos residentes en la villa que aparecen con este apellido en la documentación vista para este estudio: Salamon, Simuel y su hijo Acach.

De Salamon Samarel sólo se sabe que, el 16 de junio de 1491, nombró procuradores generales, sin revocar otros que tuviera, a Juan Navarro, Martín López, Pedro Pérez de Añón, Mateo de Albelda y Miguel Mainar, notarios causídicos de Zaragoza, y a los judíos de esta misma ciudad, Jusua Cedosillo y rabí Ezdra Crabito, ausentes ${ }^{814}$.

${ }^{807}$ Dicho leg., fols. 3v-4: Gaspar de Val, de Zaragoza, el 8 de noviembre de 1486 en dicha ciudad.

${ }^{808}$ Parece que vivía en junio de 1487, cuando testificó Rahel, y que había muerto en julio del año siguiente, cuando lo hizo Jaime.

809 C.APN., Juan Remón, 1484, fols. 27 y 348.

810 L.A.APN., Miguel Contín, 1492, fol. 25.

811 Dicho notario y año, fols. 82 y 83 .

${ }^{812}$ Dicho notario y año, fol. 56.

${ }^{813}$ Dicho notario y año, fol. 23.

814 "Et prendio quinyan segunt ley de judios, quinyan gamur mat (sic) san en poder de Simuel Albala” (dicho notario, 1491, fol. 60). 
Por lo que se refiere a Simuel Samarel, del que ignoro el parentesco que pudo tener con Salamon, vivió en unas casas de la villa que en 1485 lindaban con las de Miguel Guiralt, con las de rabí Mosse Carillo, de Arándiga, y con un callizo que no tenía salida. En 1489 las casas de Simuel lindaban con las de Bartolomé Ximeno y de su mujer María de Almudévar ${ }^{815}$, y en 1492 sus casas y corral en la judería lo hacían con el huerto de Juce Taboch ${ }^{816}$. ¿Fueron dos las casas que poseyó Simuel, una en la judería y otra fuera de ella?

Además de sus casas Simuel fue dueño de un campo en La Vega del Hospital, otro en La Vega de La Almunia, un majuelo en La Carrera La Glera, otros dos en El Romeral ${ }^{817}$ y una viña en El Ontinar ${ }^{818}$. A medias con su hijo Acach, Simuel poseyó otro majuelo en Los Medianos.

Aunque el 25 de noviembre de 1482, Simuel entregó en comanda a los labradores Martín Millán y Pero Castillo, de Ricla, nueve cahíces una arroba de trigo ${ }^{819}$, posibles dificultades económicas pudieron ser la causa de que Simuel Samarel decidiera desprenderse de algunas de sus propiedades inmuebles. El 13 de septiembre de 1485, siendo adelantado de la aljama, Simuel vendió al labrador Domingo de Dueñas, por ciento cincuenta sueldos, sus dos campos, el de La Vega del Hospital y el de La Vega de La Almunia, libres de cargas, "excepto de las cargas ordinarias de la villa»; respondió Simuel de la cantidad recibida con sus casas ${ }^{820}$. Y el 28 de febrero del año siguiente, Simuel y su hijo Acach vendieron a otro labrador de Ricla, Lorenzo del Campo, su majuelo de Los Medianos, libre de cargas, por doscientos sueldos de precio, de los que respondió Simuel con sus casas y Acach con su majuelo de La Carrera La Glera. Ese mismo día, Lorenzo del Campo vendió a Acach una viña suya, libre de cargas, sita en este mismo término, cuyos lindes

${ }^{815}$ Que, a su vez, lo hacían con las de Simuel Albala y con carrera pública (dicho notario, 1489 , fol. $1 \mathrm{v}$ ).

${ }^{816}$ Dicho notario, 1492, fol. 81. Con unas casas de Simuel lindaban las del escudero Gil de Vart en dicho año (C.APN., Forcén López, 1492, fol. 73).

817 L.A.APN., Miguel Contín, 1491, fols. 14-14v y 82.

818 Dicho notario, 1482, fol. 7.

819 Respondió de ellos Martín con un par de yeguas, una de pelo «royo y la otra gaca [sic]", y Pero con un par de vacas de pelo "royo" (dicho notario, 1482, fols. $12 \mathrm{v}-13)$.

${ }^{820}$ Dicho notario, 1485 , fols. $70-70 \mathrm{v}$. 
coincidían con los del majuelo de Acach que servía de garantía de la venta anterior y cuyo precio fue también doscientos sueldos ${ }^{821}$.

Las cosas debieron de mejorar para Simuel Samarel porque, el 6 de marzo de 1487, compró a Juan del Campo y a su mujer Benedita Serón el majuelo, libre de cargas, de La Carrera La Glera, también por doscientos sueldos ${ }^{822}$.

No fueron pocas las veces que Simuel Samarel entregó a cristianos y moros de La Almunia, Calatorao, Almonacid y Cariñena, dinero y trigo en comandas, algunas de las cuales no le fue fácil recuperar. Éste fue el caso de Juan de Tudela, mayor, que le debía setenta y cinco sueldos y se ausentó de la villa, temporalmente parece, dejando a su hijo sus bienes. El 19 de septiembre de 1486, el mozo Juan de Tudela, menor, como era justo que si tenía los bienes de su padre pagara sus deudas, juró dar a Simuel sesenta sueldos: la mitad pasados seis meses y la otra mitad en el plazo de un año. Simuel prometió, a su vez, que si le pagaba esta cantidad, él le vendería la carta de comanda en la que su padre estaba obligado. En el caso de que el deudor volviera a la villa y pagara, su hijo quedaría libre del juramento hecho y si éste había pagado parte de la deuda, Simuel se la devolvería antes de vender la carta de comanda al verdadero deudor ${ }^{823}$.

Un mes después, concretamente el 22 de octubre, Simuel entregó en comanda a Alfonso Golzálvez y a su mujer María de Estanes cuatro cahíces de trigo ${ }^{824}$. Cinco días después, el 27 de octubre en Calatorao, Simuel dio a Ali de Ovequar y a su mujer Fatima la Bazia, moros del lugar, setenta y dos sueldos ${ }^{825}$. El 15 de febrero de 1491, Haçan de Celi y Hamet de Moraquo, moros de Almonacid,

${ }^{821}$ Respondió de ellos Lorenzo con sus casas de La Almunia y su viña de El Plano (dicho notario, 1486, fols. 23-24).

${ }^{822}$ Respondió de ellos el matrimonio con un majuelo en El Romeral y otro en Los Medianos (dicho notario, 1487, fols. 17v-18).

${ }^{823}$ Dicho notario, 1486, fols. 77-77v. El 15 de octubre Simuel recibía del labrador Juan de Tudela, menor, treinta sueldos (dicho notario y año, fols. 96-96v).

${ }^{824}$ Que pagarían, la mitad en agosto de 1487 y la otra mitad en dicho mes del año siguiente. Respondió de ellos el matrimonio con sus casas en Barrio Verde y con una ternera de pelo fosco (dicho notario, 1486, fols. 100v-101). El 29 de agosto de 1487, Simuel canceló la comanda (dicho notario, 1486, fol. 100v, al margen).

${ }^{825}$ Respondió de ellos el matrimonio con un huerto en El Regacho y un campo en El Puente del Soto, términos del lugar (dicho notario y año, fol. 102v). 
recibieron de Simuel ciento catorce sueldos ${ }^{826}$. Y el 16 de marzo de 1492, éste dio del mismo modo a Agustín Monge, de Calatorao, y a Andrés Rubio, menor, de Cariñena, treinta sueldos ${ }^{827}$.

No recoge la documentación consultada para este estudio noticia alguna más sobre Simuel Samarel - aparte de su asistencia a la reunión de la aljama del 3 de mayo de 1483 y de su nombramiento como tachador de la pecha en abril de 1486, como se ha visto-, que vivió los días de la expulsión y que fue amigo del judío zaragozano Mosse Abuzmel, alias Chamorro ${ }^{828}$.

Por lo que atañe a su hijo Acach Samarel, se casó con una hija de "Çidilla», pues como yerno y procurador de ésta actuó el 5 de abril de 1486, al recibir del zaragozano Juan de Calderón, factor de Pero Pérez, todo el precio del loguero del granero de su suegra, que tenía arrendado desde el 9 de febrero de 1482 hasta entonces ${ }^{829}$. Al no especificar el notario el apellido de ésta ni su estado civil, pienso que se trataba de la viuda de Salamon Almalcani -única judía con este nombre que aparece en la documentación consultada para este estudio-, con cuyas casas y las de su hijo Jehuda Almalcani lindaban las de Acach Samarel y su mujer en $1491{ }^{830}$.

Acach Samarel que, junto con su padre, había sido dueño de un majuelo en Los Medianos, poseyó, además, otro en La Carrera La Glera ${ }^{831}$, y una viña ${ }^{832}$, un majuelo ${ }^{833}$ y un albar en El Romeral. Este último que estaba libre de cargas, se lo vendió a Acach el

${ }^{826}$ Respondió de ellos Haçan con sus casas y un huerto en Menustruel y Hamet con un majuelo en El Camino de Cosuenda, términos del lugar (dicho notario, 1491, fols. 22-22v). El 1 de julio de 1493, Jaime de Matas, como procurador del conde de Ribagorza y sustituyendo al caballero mosén Juan Ximeno, canceló la comanda (dicho notario, 1491, fols. 22-22v, al margen).

${ }^{827}$ Respondió de ellos Agustín con sus casas del lugar y Andreu con una viña en La Carrera de Tosos, término de Cariñena (dicho notario, 1492, fols. 28-28v).

${ }^{828}$ El 29 de abril de 1492 en Zaragoza, el rebolero Mosse Abuzmel reconoció tener en comanda del escudero zaragozano Juan de Tarazona dos mil seiscientos sueldos. De la cantidad recibida respondió Mosse con los mil quintales de zumaque que tenía en casa de Samarel y con los mil que tenía en la morería de Saviñán, en casa de Avdalla Alrrillena, hijo de la "alaminesa» (Z.APN., Miguel de Villanueva, 1492, fols. 258-258v). Mosse era hijo del rico judío mercader Juce Abuzmel.

${ }^{829}$ L.A.APN., Miguel Contín, 1486, fol. 31.

${ }^{830}$ Dicho notario, 1491, fol. $81 \mathrm{v}$.

831 Dicho notario, 1487 , fol. $17 \mathrm{v}$.

${ }^{832}$ Dicho notario, 1488 , fol. $36 \mathrm{v}$.

${ }^{833}$ Dicho notario, 1492, fol. 80. 
escudero Ochona de Ortubia y su mujer Beatriz de Archant por quince sueldos, el 5 de marzo de $1492^{834}$.

Dos años antes, concretamente el 10 de mayo de 1490, Acach Samarel había comprado a Johanan Frances los cuatrocientos sueldos que a éste le adjudicó el rey por su intervención como árbitro en la sentencia de los Paçagon, de Calatayud. El precio que Acach pagó a Johanan fue, como ya he dicho, otros cuatrocientos sueldos.

Como en el caso de su padre Simuel, no hay alusión alguna que permita vislumbrar cuál fue la intención y propósito de Acach Samarel, una vez conocido el edicto de expulsión, respecto al mismo.

\section{Serrano}

En la documentación vista para este estudio únicamente aparece un judío con este apellido, Acach Serrano. De Acach sólo se sabe que vivió en unas casas de la villa, que lindaban con las del labrador Pedro Moreno y de su mujer María Martínez que, a su vez, lo hacían con el huerto de Alazar Ferrer ${ }^{835}$. Dado que las casas de Acach aparecen citadas al disponer dicho labrador de las suyas el 19 de julio de 1492, creo que estaba en la villa cuando se promulgó el edicto de expulsión ${ }^{836}$ y que salió de allí con los demás judíos ${ }^{837}$.

\section{Taboch}

En la documentación vista para este estudio sólo aparece un judío con este apellido que residiera en la villa, Juce Taboch ${ }^{838}$. Juce Taboch se casó con Mira Nazir. El matrimonio vivió en unas

${ }^{834}$ Dicho notario y año, fols. 25-25v. Recuérdese que el nombre del escudero vendedor y el apellido de su mujer eran los que se puso Jehuda Almalcani cuando se convirtió, posiblemente por haber sido sus padrinos o haber influido en su conversión.

${ }^{835}$ Dicho notario, 1491, fol. 82.

${ }^{836}$ Dicho notario, 1492, fol. 80.

837 Cuando el 3 de octubre de 1492, el labrador Pedro Moreno recibió en comanda un cahíz siete fanegas de trigo, del mercader zaragozano Antón de Maluenda, respondió de ello con sus casas, que lindaban con las que fueron del judío Serrano y con carrera pública (dicho notario y año, fol. 104v).

${ }^{838}$ Con anterioridad lo haría Acach Taboch, alias Jaco, que, en alguna ocasión en 1444, entregó comandas a moros de Calatorao (véase Calatorao, II, 181-182). 
casas de la villa, que en 1488 lindaban con las de Salamon Baylo, con el corral del carnicero Juce Carillo y con carrera pública. Tenía también Juce un huerto en la judería, que en 1492 lindaba con corral y casas de Simuel Samarel, con corral de Pedro Moreno y con carrera pública. Juce y Mira eran dueños, además, de una viña en El Ginestar, libre de cargas.

La situación económica del matrimonio no debía de ser buena. El 12 de febrero de 1488, Juce Taboch y Mira Nazir vendieron su viña al escudero Tomás Cornell, señor de la casa de Mareca, por sesenta sueldos, de los que respondieron con sus casas ${ }^{839}$.

Promulgado el edicto de expulsión, el matrimonio resolvió salir con los demás judíos de la villa, según se deduce de la venta que Juce hizo de todos sus bienes.

El 19 de julio de 1492, Juce vendió al escudero Ochona de Ortubia su huerto de la judería y todos los bienes muebles e inmuebles que le pertenecieran, por los que recibió quinientos sueldos ${ }^{840}$.

Ese mismo día, Juce Taboch nombró procurador suyo a Ochona, sin revocar otros que tuviera, para demandar, recibir y cobrar, en su nombre, cualquier bien o cuantía que le perteneciera o se le debiera; para otorgar albaranes, si cobraba, y para intervenir por él en cualquier pleito que pudiera sugir ${ }^{841}$.

\section{Usillo}

En la documentación vista para este estudio sólo aparecen dos judíos con este apellido ${ }^{842}$ que residieran en la villa: Sento Usillo y su hijo Acach.

Sento Usillo se casó con Ester Cortes y, al menos, tuvieron un hijo, Acach. Vivió el matrimonio en unas casas con porche, de la

839 Dicho notario, 1488, fols. 11v-12. El 3 de febrero de este mismo año en Calatayud, Juce actuó como testigo instrumental (C.APN., Juan Remón, 1488, fol. 24v).

${ }^{840}$ L.A.APN., Miguel Contín, 1492, fol. 81.

841 Dicho notario y año, fol. $81 \mathrm{v}$.

${ }^{842} \mathrm{El}$ mismo que llevaba Abraham o maestre Abraham Usillo, uno de los judíos que presenciaron las circuncisiones de conversos que se llevaron a cabo en la judería de Huesca, entre los años 1464-1466. A maestre Abraham me referí en mi artículo Relación, I, 64-65 y 68-69. 
judería, que en 1486 lindaban con las de Juce Frances, mayor ${ }^{843}$, y con el hospital de los judíos; con casas de los herederos de Abraham Frances y con carrera pública en $1491{ }^{844}$. Fue dueño el matrimonio, también, de un albar en El Plano y un majuelo en Candenavas ${ }^{845}$.

Aunque no con mucha frecuencia, pero siempre en Calatorao, Sento Usillo hizo entregas, unas veces en dinero y otras en trigo, a cristianos y moros de ese lugar. El 21 de noviembre de 1486, entregó a Fernando de Aguilar y a su mujer María de Pastrana cien sueldos ${ }^{846}$. El 25 de ese mismo mes del año 1488, dio a Haya de Alpastiel y a Mahoma Carneron dieciséis cahíces de trigo ${ }^{847}$. El 17 de marzo de 1490, entregó a Brahem de la Teressa y a su mujer Fatima de Ceni ocho cahíces y medio de dicho grano ${ }^{848}$. Y el 7 de octubre de 1491, dio a Juce el Carnicero cien sueldos ${ }^{849}$.

Es posible que los gastos que llevó consigo la enfermedad de Sento fueran la causa de que, el 14 de octubre de 1491, él y Ester vendieran al labrador Miguel Tejedor, mayor, su albar de El Plano, libre de cargas, por veinticuatro sueldos; de los que el matrimonio respondió con sus casas de la judería ${ }^{850}$.

La muerte de Sento debió de tener lugar el 26 o 27 de noviembre de ese año porque, precisamente el día 27, el notario y los testigos se personaron en el porche de sus casas por un triste motivo. Les salió al encuentro Acach Usillo y les mostró a su padre que

«estava muerto en meytat del porche ... et mortallado». Luego "descubrio la cara del dicho su padre defunto", y el notario y los testigos «al ojo vehimos muerto et conocimos ser el dicho Yento

\footnotetext{
${ }^{843}$ Dicho notario, 1486 , fol. $68 \mathrm{v}$.

844 Dicho notario, 1491, fol. 89.

${ }^{845}$ Dicho notario, 1484, fol. 1v.

${ }^{846}$ Respondió de ellos el matrimonio con sus casas, que lindaban con la Puerta del lugar (dicho notario, 1486, fol. 111).

${ }^{847}$ Dicho notario, 1488, fol. 90v; el instrumento no termina. El 23 de septiembre de 1490 en Épila, Sento recibió de Yahie de Alpastiel y de Mahoma Carneron, vecinos de Calatorao, pero "de present» en la villa de Épila, los dieciséis cahíces de trigo y un cahíz de bisaltos que le debían, según comanda hecha el 25 de noviembre de 1488 en La Almunia (Z.APN., Antón de Abiego, 1490, fol. 94).

${ }^{848}$ Respondió de ellos el matrimonio con un huerto «a la Puerta el Pozo» (L.A.APN., Miguel Contín, 1490, fol. 32v).

849 Respondió de ellos Juce con sus casas del lugar (dicho notario, 1491, fol. 83).

${ }^{850}$ Dicho notario y año, fols. $88 \mathrm{v}-89$.
} 
Usillo, jodio, al qual en vida muy bien conocimos et conocimos ser el dicho Yento Usillo et ser aquel muerto".

A continuación, como Acach necesitaba probar «en tiempo sdevenidor" que su padre había muerto, pidió al notario que levantara acta ${ }^{851}$.

Ésta es la última noticia que la documentación vista aporta sobre Sento, que en la reunión de la aljama del 11 de abril de 1486 fue nombrado sobretachador de la pecha. Su mujer e hijo vivieron posiblemente los días de la expulsión.

\section{Xeteni}

En la documentación vista para este estudio sólo aparecen dos judíos con este apellido que residieran en la villa: Acach y el tejedor Juce Xeteni.

Acach Xeteni vivió en unas casas de la judería que lindaban con las de Acach de la Fuent ${ }^{852}$ y con las de Acach Abenforna ${ }^{853}$. Era dueño, además, de otras propiedades inmuebles: unas casas en la villa que lindaban con las de los herederos de Simón de Septiembre, con las de Miguel Guiralt y con carrera pública ${ }^{854}$; un campo en La Vega del Hospital ${ }^{855}$, un yermo en El Ginestar ${ }^{856}$, un albar en Candenavas ${ }^{857}$ y una viña en El Romeral ${ }^{858}$.

Acach Xeteni acostumbró dar comandas en dinero y grano a labradores cristianos y a moros, de la villa o de los lugares cercanos a ésta: el 1 de septiembre de 1480, entregó a Simón Ibáñez setenta sueldos, quien prometió devolverlos hasta el día de San Gil del año siguiente ${ }^{859}$; el 20 de marzo de 1483, dio a Domingo López, Juan Escribano y al alfaqui Mahoma Cambriel, vecinos de Ricla, siete

${ }^{851}$ Dicho notario y año, fols. 107-107v.

${ }^{852}$ Dicho notario, 1485, fol. 81v y 1488, fol. 23.

${ }^{853}$ Dicho notario, 1486, fol. 43 y 1488, fols. $28-28 \mathrm{v}$.

${ }^{854}$ Dicho notario, 1488, fol. 38.

${ }^{855}$ Dicho notario, 1486, fol. 69v.

856 Dicho notario y año, fol. $111 \mathrm{v}$.

857 Dicho notario, 1487, fol. 6v.

${ }^{858}$ Dicho notario, 1491, fol. 95v.

859 Respondió de ellos Simón con una asna de pelo cárdeno y un pollino de pelo pardillo (dicho notario, 1480, fols. 13-14v). 
cahíces una fanega de trigo ${ }^{860}$; el 13 de enero de 1484 en Calatayud, entregó al labrador bilbilitano Juan Romero noventa sueldos ${ }^{861}$; el 9 de abril dio al labrador Pedro de Orihuel ochenta sueldos ${ }^{862}$; el día 30 entregó a Brahem el Carnicero, moro de Calatorao, dos cahíces y medio de trigo ${ }^{863}$; y el 6 de diciembre, a Juan Pascual y Domingo Cebrián, de Cosuenda, dos cahíces y medio del dicho grano; Domingo juró que le pagaría sesenta sueldos hasta la siguiente fiesta de San Juan ${ }^{864}$. En 1485 Acach entregó las siguientes comandas: el 4 de enero, a Remón de Urgel y Domingo Rasera, hijo de Martín, catorce florines de oro ${ }^{865}$; el 3 de junio, a Vicente Salillas y a su mujer Juana Galindo un cahíz de trigo y cuatro de cebada ${ }^{866}$; y el 29 de julio le pagaron Martín Rasera y Antón Quílez, de Épila, trescientos cincuenta sueldos de los setecientos que le debían a él y a Simuel Albala ${ }^{867}$.

Todas estas entregas en comanda terminaban con su cancelación y otorgamiento de albarán, cuando lo dado se devolvía; con el otorgamiento de poderes para lograr su cobro, como hizo Acach, el 13 de julio de 1485 en Calatayud, al nombrar procurador suyo a Juan Remón para cobrar y otorgar albaranes «et ad lites» ${ }^{868}$; con la adquisición de bienes inmuebles con los que el deudor respondía, cuando éste no pagaba; o con el recurso de arbitraje, cuando el deudor no estaba de acuerdo con lo que el acreedor exigía que le abonase. Este último caso fue el que se dio entre Acach Xeteni y uno de sus deudores, Martín Rasera, que sería con el tiempo comi-

${ }^{860}$ Respondió de ellos Domingo con un mulo de pelo negro, Juan con un rocín de pelo castaño y Mahoma con un potro de pelo bermejo (dicho notario, 1483, fol. $17 v)$.

${ }^{861}$ C. APN., Juan Remón, 1484, fols. 33-33v.

${ }^{862}$ Respondió de ellos Pedro con un majuelo en El Romeral (L.A.APN., Miguel Contín, 1484, fol. 15v). El 22 de junio de 1486, Acach canceló esta comanda y otorgó albarán (dicho notario, 1484, fol. 15v, al margen).

${ }^{863}$ Respondió de ellos Brahem con sus casas (dicho notario y año, fols. 18v-19).

${ }^{864}$ Respondió de ellos Juan con sus casas de Cosuenda y Domingo con un majuelo en Navasillos, término de dicho lugar (dicho notario y año, fol. 66).

${ }^{865}$ Dicho notario, 1485 , fols. $4 \mathrm{v}-5$.

${ }^{866}$ Respondió de ellos el matrimonio con un par de vacas, una baya y otra fosca, y el sementero que tenía en La Huerta y Los Montes de la villa, y en el término de Cabañas (dicho notario y año, fols. 41-4lv).

${ }^{867}$ Según comanda hecha el 28 de agosto de 1482, ante el notario Pero López (L.A.APN., Miguel Contín, 1485, fols. 51 v-52).

${ }^{868}$ C.APN., Forcén López, 1485, fol. 224. 
sario real de la expulsión de los judíos de la villa, junto con Jaime de Matas.

El 25 de agosto de 1485, como pleitos, debates y cuestiones, civiles y criminales, se esperaba que surgieran entre dichos Martín y Acach, aconsejados por buenas personas "por bien de paz et de concordia», nombraron árbitros para que los dilucidaran al escudero Luis Navarro y a Johanan Frances, quienes deberían emitir la sentencia ${ }^{869}$ durante el mes de septiembre, sin posibilidad de prorrogar el plazo de emisión. Los dos litigantes prometieron cumplirla y se obligaron a hacerlo con sus bienes, bajo pena de cien florines de oro, que se dividirían en tres partes: una para el rey, otra para los árbitros y la tercera para el litigante que cumpliera lo ordenado en dicha sentencia ${ }^{870}$. El 20 de septiembre Luis Navarro y Johanan, árbitros y amigables componedores entre Martín Rasera y Acach Xeteni, emitieron la siguiente sentencia: $1^{\mathcal{Q}}$, Martín tenía que pagar a Acach, durante el mes de septiembre, cien sueldos y cuatro más por "la fechura de la carta»; con ellos Acach y Simuel Albala, o sus herederos, les otorgarían albarán de trescientos cincuenta de los setecientos sueldos que les debían Martín y Antón Quílez, vecino de Epila -según comanda hecha el 28 de agosto de 1482 ante el notario Pero López-; si Martín no pagaba en el plazo ordenado, ni Acach ni Simuel tenían que otorgar albarán, que sólo entregarían dos días después de haber cobrado; $2^{2}$, Martín tenía que pagar a Acach dos fanegas de trigo en dicho mes de septiembre; $3^{\circ}$, como entre Martín y Acach existía discrepancia sobre nueve fanegas de trigo, Martín tenía que jurar que no las debía y sería absuelto; si no juraba, tenía que pagarlas en el mes de septiembre o quince días después de emitida la sentencia; y $4^{\circ}$, los árbitros valoraron sus trabajos en sendos pares de perdices, que ya habían recibido, y los del notario, por testificar la sentencia e intimarla, en doce sueldos, que pagarían entre los dos contrincantes, pero si algún acto más testificaba, lo pagaría el solicitante ${ }^{871}$.

Al día siguiente de hacerla pública y por orden de los dos

${ }^{869}$ «De noche o de dia, asentados o en pies, en dia feriado o no feriado, en la forma et manera a ellos bien vista, etc.».

870 L.A.APN., Miguel Contín, 1485, fols. 64-64v.

871 Dicho notario y año, fols. 72v-73v. Recuérdese que Simuel Albala, como procurador del escudero valenciano Leonardo Roiz, vendió a Martín Rasera y a Antón Quílez un censo, el mismo 20 de septiembre de 1485 , como se ha visto al hablar de Simuel. 
árbitros, el notario Miguel Contín intimó la sentencia a los litigantes, "de verbo ad verbum lehi et publique», quienes la «loharon et aprovaron" en su totalidad ${ }^{872}$.

Los problemas por falta de pago que pudieron acarrearle a Acach Xeteni las comandas entregadas no fueron óbice para que dejara de darlas.

En el transcurso del año siguiente al en que se emitiera la sentencia, 1486, Acach entregó en comanda y recibió el pago de las siguientes: El 8 de enero le pagaron Juan Pascual y Asensio Lorente, de Alpartir, ciento veinte sueldos de los doscientos cuarenta que le debían ${ }^{873}$; Acach prometió entregarles el albarán de la comanda cuando le pagaran el resto ${ }^{874}$. El 25 de agosto entregó a Martín de Granollers siete cahíces de trigo ${ }^{875}$; Acach prometió que, cuando le devolviera dicha cantidad, le vendería su campo de La Vega del Hospital por cien sueldos,

«los quales vos me pagays et pagareys pagandome la suso dicha carta de comanda" ${ }^{876}$.

Esta promesa me induce a pensar que el dueño del campo era realmente Martín y había pasado a ser propiedad de Acach por falta de pago. Y el 29 de diciembre Acach entregó a Miguel Gastón cinco cahíces de trigo y diez fanegas de cebada ${ }^{87}$.

A principios del año siguiente, concretamente el 23 de enero de 1487, Acach Xeteni compró a Sancho Martínez y a Antón de Salas su albar de Candenavas, libre de cargas, por treinta sueldos ${ }^{878}$. Días después, el 1 de febrero, Acach defeneció y absolvió a Simón López y al difunto Juan Diago, de Inoges, y a sus bienes, de los ciento doce sueldos y diez fanegas de trigo que le debían ${ }^{879}$ y que había

${ }^{872}$ Dicho notario y año, fol. 74.

${ }^{873}$ Según comanda hecha el 7 de diciembre de 1466 en La Almunia, ante el notario Juan de Cuéllar.

874 L.A.APN., Miguel Contín, 1486, fols. 5-5v.

${ }^{875}$ Que pagaría, la mitad en agosto de 1487 y el resto en dicho mes del año siguiente. Respondió de ellos Martín con una viña en La Cuesta.

${ }^{876}$ Dicho notario y año, fols. 69-69v.

877 Dicho notario, 1487 -recuérdese que el año empezaba el 25 de diciembre-, fols. $2-2 v$.

878 Dicho notario, y año, fols. $6 \mathrm{v}-7$.

879 Según comanda hecha el 11 de octubre de 1473 en La Almunia, ante el notario Pero López. 
recibido a través de Asensio Gastón, vecino de dicho lugar, que entonces era "detenedor" de los bienes de los dos deudores ${ }^{880}$.

En el año 1488 Acach resolvió desprenderse de las casas que tenía en la villa fuera de la judería. El 25 de agosto se las vendió, libres de cargas, a Pedro Ximénez por doscientos sueldos ${ }^{881}$. El motivo de la venta no parece que fuera el económico, porque durante este mismo año Acach entregó las siguientes comandas: el 23 de octubre, a Miguel Tejedor, menor, y a su mujer Catalina García once cahíces y medio de trigo ${ }^{882}$; el 3 de noviembre, al labrador Pedro Casado cinco cahíces de trigo y doce sueldos ${ }^{883}$; el día 12, al labrador Domingo Tena y a María García, viuda de Juan Catalán, tres cahíces seis fanegas ${ }^{884}$; y el 19 del mismo mes, al labrador Pedro Sancho la misma cantidad ${ }^{885}$.

Durante el siguiente año 1489, concretamente el 3 de abril, Acach entregó en comanda a Ali Castillo, de Lucena, seis cahíces de trigo, quien juró devolverlos en tres tandas, dos cahíces cada mes de agosto de los años 1489, 1490 y $1491{ }^{886}$. Pero Acach puso dos condiciones: $1 .^{\mathrm{a}}$,

«en caso que cesseys nenguna de las tandas suso dichas ..., seays exsecutado por todo el deudo e partiessedes con mi amor ${ }^{887}$;

y $2 .^{\text {a }}$, si Ali pagaba, él prometía entregarle todas las comandas u obligaciones que sobre él y sus bienes tuviera, cancelarlas y otorgar sus respectivos albaranes ${ }^{888}$. Y el 16 de septiembre Acach vendió a

\footnotetext{
${ }^{880}$ L.A.APN., Miguel Contín, 1487, fols. 9v-10.

${ }^{881}$ Al no responder de la cantidad recibida con otros bienes, pienso si no serían las casas, de hecho, de Pedro, y Acach se las devolvió al pagarle lo que le debía (dicho notario, 1488 , fols. $38 v-39$ ).

${ }^{882}$ Respondió de ellos el matrimonio con sus casas y un olivar en El Brazal de La Noguera (dicho notario y año, fols. 70-70v).

${ }^{883}$ Respondió de ellos Pedro con sus casas y una viña en La Carrera de Almonacid (dicho notario y año, fols. 81-81v).

${ }^{884}$ Respondió de ellos el labrador con dos campos en La Vega del Hospital (dicho notario y año, fols. 83-83v).

${ }^{885}$ Respondió de ellos el labrador con una viña en El Ginestar (dicho notario y año, fols. 86-86v).

${ }^{886}$ Respondió de ellos Ali con un campo en El Campo del Rey, término de Calatorao, y con una mula de pelo castaño oscuro.

${ }^{887}$ Lo que suponía pasar a ser dueño, de hecho, de los bienes con los que Ali respondía.

${ }^{888}$ Dicho notario, 1489, fols. 21-2lv.
} 
los labradores Pascual Ferrando y a su hermano Blasco, vecinos de Santa Cruz, los ciento ochenta sueldos que le debían ${ }^{889}$, por la misma cantidad ${ }^{890}$.

El 21 de abril de 1490 en Inoges, Acach Xeteni recibió de Antón Serrano y de su mujer Toda de Olves, vecinos del lugar y «tenedores» de los bienes del difunto Miguel de Pola, los ciento cincuenta sueldos que éste y el también difunto Domingo Fraile le debían ${ }^{891}$. Y el 1 de noviembre Acach entregó a Sancho Aznárez, menor, diez cahíces de trigo ${ }^{892}$.

Durante el año 1491, Acach Xeteni sólo entregó una comanda, el 30 de diciembre, al labrador Colás Garcés, de seis cahíces una arroba de trigo ${ }^{893}$. Acach prometió darle, cuando se los devolviera, otra carta de comanda en la que le debía cinco cahíces, pero debería abonarle los gastos de las

«fechuras ... que a mi costó de sacar en publica forma».

Por su parte, Colás juró sembrar en 1492, con el trigo recibido, el campo que ofreció como garantía y

"no poner el trigo de mi hera fasta que vos ... seays pagado» "894.

Acach Xeteni que fue uno de los asistentes a las reuniones de la aljama del 3 de mayo de 1483 y del 11 de abril de 1486, que había actuado como adelantado y clavario en 1487, que ocupaba dichos cargos en agosto de 1490 y también el de clavario en enero de 1491, no parece que viviera en los días de la expulsión, por la falta de noticias sobre él en la documentación vista de 1492.

Por lo que se refiere a Juce Xeteni, del que se ignora el parentesco que pudo tener con Acach, sólo se sabe que, el 19 de septiembre

${ }^{889}$ Según comanda hecha el 9 de enero de 1475 en La Almunia, testificada por el notario Miguel Navarro y signada por el notario Juan Navarro, "como successor de sus notas".

${ }^{890}$ L.A.APN., Miguel Contín, 1489, fols. 44-44v. Luego Pascual recibió en comanda de su hermano cuarenta y siete sueldos.

${ }^{891}$ Según comanda hecha el 24 de enero de 1472 en La Almunia, ante el notario Miguel Navarro (L.A.APN., Miguel Contín, 1490, fol. 41).

${ }^{892}$ Respondió de ellos Sancho con sus casas «a la Puerta Cabanyas» y con un campo en Los Quinones (dicho notario y año, fols. 73v-74).

${ }^{893}$ Respondió de ellos el labrador con un campo sito en La Loba y su sementero.

894 Dicho notario, 1492, fols. 1-1v; recuérdese que el año empezaba el día 25. 
de 1488, entregó también en comanda al labrador Pedro Casado tres cahíces de trigo ${ }^{895}$.

\section{Zecrit ${ }^{896}$}

En la documentación vista para este estudio sólo aparece un judío con este apellido, rabí Abraham Zecrit. De rabí Abraham únicamente se sabe que actuó como testigo instrumental, el 1 de junio de 1490, en una comanda que maestre Vidal Chinillo entregó a dos moros de Calatorao ${ }^{897}$. Posiblemente rabí Abraham Zecrit compareció ante algunos de los otros notarios de La Almunia -cuyos protocolos han desaparecido o no se encuentran allí-, al igual que hicieron otros judíos de la villa.

Además de todos los judíos citados, se sabe que vivieron en la villa en los años que abarca este estudio maestre Mayr, Caravida, que se casó con el judío bilbilitano Simuel Paçagon, y Clarica.

De maestre Mayr sólo se sabe que en 1471 sus casas, que habían sido de Miguel Guiralt, lindaban con corral de maestre Juan Serón, que compró al almadraquero Juce Claros y que, a su vez, lo hacían con corral de la mujer de Miguel Gastón, con el de Pero Serón, mayor, Pero Serón, menor, Domingo Just ${ }^{898}$ y Miguel Guiralt, y con callizo "do ha entrada et sallida» ${ }^{899}$.

La noticia que se refiere a Caravida procede de un proceso inquisitorial. En enero de 1487 en Calatayud, al pasar el judío bilbilitano Jaco Hiara por casa de María López - mujer de Pedro de Santa Cruz, que estaba preso por el Santo Oficio-, lo llamó y le dijo:

— «aestro, fazetme hun plazer, que vayais» a casa de la viuda de

${ }^{895}$ Respondió de ellos el labrador con su majuelo de El Romeral (dicho notario, 1488 , fol. 50v).

${ }^{896}$ Podría ser Zetut.

897 Dicho notario, 1490 , fol. $47 v$ (véase nota 523 ).

${ }^{898}$ Fue procurador de don Lope Ximénez de Urrea, señor de Almonacid de la Sierra, en 1472 (dicho notario, 1472, fol. 22v).

${ }^{899}$ Dicho notario, 1471 , fols. $4 \mathrm{v}-5$. 
Paçagon «e le digais que bien sabe quando yo e mi nieta, la muxer de Paulo de Sançta Çruz, fuemos a las bodas de Caravida", mujer de Simuel Paçagon, «que no nos daron collaçion e no vevimos».

Cuando Jaco transmitió el recado, le dijo Caravida:

—Como tengo de dizir que no comieron ni vevieron, si aqui comieron e vevieron"

las dos ${ }^{900}$. Interrogada al respecto María, dijo que cuando estuvo en casa de dicho Simuel, que casó con una judía de La Almunia, para visitarla,

«sacaronle collaçion de rosquetas y truxo un par dellas a su casa» ${ }^{901}$.

Como en el caso de Caravida, la noticia de Clarica la proporciona un proceso inquisitorial. Clarica, oriunda de La Almunia, fue moza del sastre Salamon Carruch y de su mujer Oro, en Calatayud. La amistad de este matrimonio con el sastre converso Pedro Ferrer y con su mujer Catalina de Funes ${ }^{902}$ fue el motivo de que Pedro rogara a Salamon que le enviara pan cenceño, turrado y «alcahalillas» en la pascua judía del cenceño. Desde 1480 la encargada de llevar el presente fue Clarica, quien lo entregaba a Catalina; luego Pedro le comentaba a Salamon que le había "supido bueno" 903.

TÉRMINOS DE LA VILLA DONDE LOS JUDIOS TENIAN PROPIEDADES INMUEBLES

Además de ser dueños de sus casas ${ }^{904}$, gran parte de los judíos fueron propietarios -como los demás vecinos de la villa- de campos de secano o regadío, sitos en su mayor parte en los términos que circundaban a ésta. Los nombres de algunos de ellos eran los mismos que los de los términos de los lugares cercanos y otros se

900 Z.AAT., leg. 16, $\mathrm{n}^{\circ}$ 4, fols. 33-33v: Jaco Hiara, el 20 de junio de 1487.

901 Dicho leg. y $\mathrm{n}^{2}$, fol. 77: interrogatorio de la acusada María López, el 20 de octubre de 1489 en Calatayud.

902 A ello aludí en Relación, I, 288.

${ }_{903}$ Z.AAT., leg. 19, $\mathrm{n}^{2}$ 3, fols. 5-5v: Acach Carruch, el 17 de junio de 1488.

904 No parece que los judíos de La Almunia poseyeran casas fuera de la villa. Según la documentación consultada, sólo Juce Carillo, hijo de Jaco, tuvo un palacio o sala en unas casas de Ricla. 
llamaban igual que las puertas de La Almunia, pues eran su prolongación.

Según la documentación correspondiente a los años que abarca este estudio, los términos donde los judíos -que nunca aparecen con el oficio de labradores- tuvieron huertos, majuelos, viñas, albares, yermos y, sólo en un caso, olivos, fueron los siguientes ${ }^{905}$ :

\section{Puerta de la Balsa}

- Juce Frances: un huerto que lindaba con el de Antón de Archant y con el de Felipe Escudero y de su mujer Toda que, a su vez, lo hacía con albar de Jaime de Matas; otro huerto en Las Eras de dicha Puerta, que lindaba con el de la cofradía de San Miguel y con la "tallada", carrera en medio ${ }^{906}$; un tercero, que lindaba con majuelo de la viuda Antona Escudero que, a su vez, lo hacía con albar de Jaime de Matas y con carrera pública; y un cuarto huerto - podría ser el mismo anterior-, que lindaba con un majuelo cerrado, de dicha viuda y de su hijo Miguel de Almudévar que, a su vez, lo hacía con campo de Jaime de Matas.

\section{Puerta de Cabañas}

- Simuel Pardo: un huerto que lindaba con el de Tomás Cornell, con el de Fernando del Pozo y con La Acequia del Jalón.

\section{Candenavas ${ }^{907}$}

- Mosse Abenforna: una viña en La Carrera de La Dehesa, que lindaba con ésta, con albar de la viuda de Pero Serón y con viña de Habehut, moro de Ricla; y un majuelo que lindaba con su viña y con La Carrera de Alpartir.

${ }^{905}$ Las notas correspondientes a estos campos aparecen en la parte de este estudio donde me referí a cada uno de sus propietarios; a ellas remito al lector para evitar repeticiones inútiles.

906 Podría ser el mismo que, sito "de çaga del muro", lindaba con el de dicha cofradía que, a su vez, lo hacía con "cenya" de Juan de Curiel (L.A.APN., Miguel Contín, 1484, fol. 63v).

907 Otras veces aparece este término como Carrera de Muelarroya. 
- Jaco Abiayut: una viña que lindaba con la de Juan Murero, con majuelo de Miguel Gastón y con sendero.

- Salamon Albala: una viña que lindaba con la del barbero García Alonso que, a su vez, lo hacía con majuelo de mosén Juan Ximeno. - Cidiella Anuadaya: una viña que lindaba con la de Juan López, vecino de Ricla, que lo hacía, a su vez, con la de Pedro de Orihuel.

- Cidiella Anuadaya y su hijo Jehuda Almalcani: una viña que lindaba con la de Sancho Aznárez, con Carrera de Muelarroya y con «la joya» de Pedro de Orihuel.

- Jehuda Almalcani: un majuelo que lindaba con viña de Miguel Gastón y con viña de Alonso Daza.

- Juce Carillo: una viña que lindaba con la de Juan de Álvarez y con la de Mosse Abenforna; otra que lindaba con la de Pedro de Orihuel, llamada La Joya, y con Carrera de Muelarroya; y una tercera que lindaba con majuelo de Antón de Archant y con viña de Juan Compañón.

- Alazar Ferrer: una viña que lindaba con la de Miguel Gastón, con la de la viuda de Miguel de Longares y con La Acequia de Gríu ${ }^{908}$. - Johanan Frances: una viña que lindaba con majuelo de Domingo de Dueñas que, a su vez, lo hacía con viña de Antón Contín; otra viña «ius» la acequia, que lindaba con «mullon» de Felipe Escudero, con viña de Rodrigo de Quintanilla y con la de la viuda de Juan García de Trasobares; y un majuelo en Carrera de Muelarroya, que lindaba con carrera pública, rasa en medio, y con majuelo de Martín de Estremera.

- Juce Frances: un majuelo en Carrera de Muelarroya, que lindaba con el de Martín de Estremera, con el de Acach de la Fuent y con

908 La Acequia de Gríu estaba cerca del término de El Fosar de los Judíos. Con ella y con carrera pública lindaba una viña de Pero Serón, menor, y de su mujer Juana del Campo, sita en Carrera de Almonacid (dicho notario, 1483, fol. 36v). Dicha acequia había dado también nombre a un término de la villa, donde tenía un olivar el labrador Fernando del Pozo, que lindaba con el de Juan García y con el de Gonzalvo Gil (dicho notario, 1484, fol. 10); otro, Juan Escudero y su mujer Catalina de Montesa, que lindaba con el de mosén Juan Ximeno, con el de la capellanía de Arbués y con El Brazal de la Cruz (dicho notario y año, fol. 11v); y otro, el labrador Juan Moreno, que lindaba con el de Ferrando Juan, con el de Domingo Pascual y con dicha acequia (dicho notario y año, fol. 23v). Gríu era también término de Ricla; alli, "al barranco", tuvo un olivar el citado Juan Escudero y su mujer Catalina, que lindaba con el de la capellanía de mosén Pedro Ximeno, con el del señor don Francisco de Luna, "con cequia regant y el rio al suelo" (dicho notario y año, fol. 11); y otro, "a los barrancos», Pero Serón, que lindába con el de Mateo de Luna y con olivar de herederos de Juan de Albornoz (dicho notario, 1497, fol. 80v). 
rasa; y otro majuelo en la misma Carrera, que lindaba con viña de Acach de la Fuent, rasa en medio, con viña del labrador Martín de Estremera y con carrera pública; ambos podrían ser el mismo.

- Acach de la Fuent: un majuelo en Carrera de Muelarroya, que lindaba con el de Juce Frances que, a su vez, lo hacía con el de Martín de Estremera y con rasa; y una viña en la misma Carrera, que lindaba con majuelo de Juce Frances, rasa en medio, que, a su vez, lo hacía con viña del labrador Martín de Estremera y con carrera pública; ambos campos podrían ser el mismo.

- Benjamin Mocatil: un majuelo que lindaba con el de Domingo Álvarez y con viña de Pedro de Coca.

- Sento Usillo: un majuelo que lindaba con viña, con majuelo y yermo del tejedor Juan Martínez y de su mujer Catalina García que, a su vez, lo hacía con viña de Pedro de Orihuel y con dos carreras.

- Acach Xeteni: un albar que lindaba con viña de Miguel Gastón, con majuelo de Alonso el Pellicero y con Carrera de Muelarroya.

\section{Carrera de Cariñena}

- Simuel Pardo: una viña que lindaba con la de Felipe Escudero y con la carrera, «rasa a la cabeça».

\section{«a Cenya»}

- Juce Frances: un huerto que lindaba con el del notario Juan Navarro, que era treudero a la cofradía de San Miguel y que, a su vez, lo hacía con viña de Juan de Curiel «al suelo».

- Jaco Mocatil: una viña que lindaba con la de Juan de Curiel y con huerto de Pero Serón.

\section{La Cuesta}

- Jaco Albala: un majuelo que lindaba con viña de Mateo de Granollers que, a su vez, lo hacía con majuelo de Johanan Frances y con "tapias que antigamente solian estar».

- Sento Amato: un yermo que lindaba con majuelo del labrador 
Juan de Álvarez que, a su vez, lo hacía con el majuelo de Pascual de Ateca.

- Salamon Cohen: una viña que lindaba con majuelo tapiado de herederos del difunto Martín de Almazán, con La Acequia del Jalón, con sendero de La Cuesta y con yermo. Cabe en lo posible que esta viña perteneciera a Mosse Cohen.

- Johanan Frances: una viña que lindaba con la de Violante de Blanes, viuda de Pedro de San Juan, que lo hacía, a su vez, con la de Domingo de Calatayud; un majuelo o viña que lindaba con viña de Mateo de Granollers que, a su vez, lo hacía con majuelo de maestre Jaco Albala y con "tapias que antigamente solian estar»; y otro majuelo - podría tratarse del anterior- que lindaba con el de Jaco Albala y con viña del especiero Alonso Perales.

\section{El Ginestar ${ }^{909}$}

- Salamon Abendada: una viña que lindaba con la de Juce Taboch y de su mujer Mira Nazir que, a su vez, lo hacía con la del escudero Tomás Cornell, señor de Mareca, rasa en medio.

- Acach Abenforna: una viña que lindaba con la de Antón de Salas y con la de Juan Marco.

- Jaco Abiayut ${ }^{10}$ : una viña que lindaba con la de Antón de Salas, con yermo de Juan Just y con rasa.

- Jaco Albala: un majuelo que lindaba con el de Domingo de Calatayud, rasa en medio, y con viña de Bartolomé Ximeno.

- Jehuda Almalcani: un majuelo que lindaba con viña de Juan Escudero, con viña de Pero Palacio y con La Acequia de Gríu.

- Jehuda Alpullat: una viña que lindaba con la acequia «somera» y con La Carrera de Almonacid.

- Cidiella Anuadaya y su hijo Jehuda Almalcani: un albar que lindaba con viña de Salamon Cohen, con viña que fue de micer Sora, rasa en medio, y con carrera pública de Almonacid.

- Salamon Cohen: una viña que lindaba con la de Martín de Aznara y con La Carrera de Almonacid; y un majuelo que lindaba con albar del mozo Domingo Muniesa que, a su vez, lo hacía con viña de Martín de Aznara y con albar de Juan Just.

\footnotetext{
909 Otras veces aparece este término como Carrera de Almonacid o fincas que estaban en él se dan como sitas en dicha Carrera.

910 Recuérdese que Jaco sólo vivió "de present» en la villa.
} 
- Juce Çuri: una viña que lindaba con majuelo de Paçagon, con viña de Águeda de la Ram y con rasa.

- Juce Frances: una viña que lindaba con la de la cofradía de Santa María de los Sábados y con la de Sancho de Sangüesa.

- Juce Taboch y su mujer Mira Nazir: una viña que lindaba con otra del escudero Tomás Cornell, señor de Mareca, rasa en medio, y con la de Salamon Abendada.

- Acach Xeteni: un yermo que lindaba con albar del labrador García Casado que, a su vez, lo hacía con Carrera de El Ginestar.

\section{Carrera La Glera}

- Vidal Arruet: una viña que lindaba con la de Aljohar Cohen.

- Aljohar Cohen: una viña que lindaba con majuelo de Colás Garcés y de su mujer Águeda Gómez que, a su vez, lo hacía con viña de Felipe Escudero.

- Salamon Baylo: una viña que lindaba con albar de la viuda Antona de Ricla que, a su vez, lo hacía con albar de Colás Diago.

- Juce Frances: un albar que lindaba con viña de Antón Contín, con albar del labrador Antón Catalán y con carrera pública.

- Acach Samarel: un majuelo que lindaba con viña de Sancho Aznárez y con la de Juan del Campo.

- Simuel Samarel: un majuelo que lindaba con viña de Antón Contín, rasa en medio, con majuelo de Acach Samarel y con viña de mosén Juan Ximeno «a los piedes».

\section{La Huerta del Hospital}

- Jaco Albala: un campo que lindaba con el de Esteban de Ruescas que, a su vez, lo hacía con el de Pero Serón.

\section{Los Medianos}

- Simuel Samarel y su hijo Acach: un majuelo que lindaba con el yermo de Pero Serón y con La Acequia de Gríu. 


\section{El Ontinar}

- Simuel Samarel: una viña que lindaba con campo o albar del labrador Juan de Luna que, a su vez, lo hacía con el de Miguel Tejedor.

\section{El Plano}

- Simuel Albala: un albar que lindaba con viña de la de Juan de Losilla y con yermo de Antón de Salas.

- Vidal Arruet: un albar que lindaba con el de Pedro de Orihuel, con el de Berenguer Garcés y con Carrera de Muel.

- Sento Çarfati: una viña que lindaba con la de mosén Juan Ximeno, rasa en medio, con viña de la cofradía de Santa María de los Sábados y con albar de Benjamin Mocatil.

- Juce Carillo: una viña que lindaba con la de Simuel Pardo que, a su vez, lo hacía con campo de "Formigon"; otra que lindaba con la de Felipe de Moros y con la de Hahim Cohen; y una tercera que lo hacía con la de Felipe Escudero y con brazal de riego.

- Hahim Cohen: una viña que lindaba con la de Juce Carillo y con albar de Miguel de Almudévar.

- Hahim Cohen y su mujer Bellida de Sos: un albar que lindaba con el de Lorente del Campo, con viña de herederos de Rodrigo de Quintanilla y con rasa.

- Juce Frances: un albar que lindaba con viña de Miguel Polo y de su mujer Isabel que, a su vez, lo hacía con viña de Águeda de la Ram y con Carrera de Muel; y otro albar que lindaba con viña de Fernando Juan, con albar de Pedro de Orihuel, con Carrera de Muel y con rasa del «lodon».

- Benjamin Mocatil: un albar que lindabi con viña de Sento Çarfati que, a su vez, lo hacía con la de mo ién Juan Ximeno, rasa en medio, y con la de la cofradía de Santa María de los Sábados.

- Simuel Pardo: una viña que lindaba con la de Juce Carillo, mayor, y con campo de «Formigon".

- Sento Usillo y su mujer Ester Cortes: un albar que lindaba con el del labrador Miguel Tejedor, mayor, con viña de Águeda de la Ram y con rasa de riego. 


\section{El Pozuelo ${ }^{911}$}

- Jaco Albala: un majuelo que lindaba con el de Felipe Escudero, con el de mosén Juan Ximeno, rasa en medio, y con carrera pública.

- Cidiella Anuadaya y su hijo Jehuda Almalcani: una viña que lindaba con la del pellijero Alonso Pérez, con Carrera de Cariñena y con viña de Vicente de Leu, rasa en medio.

- Vidal Chinillo: una viña que lindaba con la del labrador Pedro Tejedor que, a su vez, lo hacía con la de Francisco de Sanantón; y otra que lindaba con majuelo del labrador Juan Escudero que, a su vez, lo hacía con majuelo de Pedro Tejedor, mayor, y con carrera pública. - Juce Frances: un yermo que lindaba con viña que María Gil aportó a su matrimonio, que lo hacía, a su vez, con viña de Ferrando Juan.

\section{Los Quiñones ${ }^{912}$}

- Jaco Albala: una viña que lindaba con la de Simuel Pardo; y un campo que lindaba con el de Sancha de Azagra, viuda del escudero Juan de Losilla, que lo hacía, a su vez, con el de Miguel Tejedor, menor.

- Simuel Pardo: una viña que lindaba con la de Miguel Guiralt y con la de Luis Navarro; otra que lindaba con la de Jaco Albala y con la acequia; y una tercera que lindaba con la de Pero Sanz y con la dicha acequia.

\section{Carrera de Ricla}

- Jaco Albala: un huerto que lindaba con el de Antón Catalán, con la acequia de riego y con La Carrera de Ricla.

- Juce Frances: una viña que lindaba con la de Martín del Pozo, con la de la capellanía de mosén Pascual de Archant y con rasa.

\footnotetext{
911 O Pozuelo.

912 Por este término pasaba el río Mediano. Con él, con campos de Remón López y con carrera de El Soto, lindaban unos campos contiguos, sitos "al pero", del enfermero de la iglesia de Santa María del Pilar, de Zaragoza (dicho notario, 1484, fol. 2). El río Mediano pasaba también por el término de La Vega del Hospital (dicho notario, 1496, fols. 33v, 60 y 78v, y 1497, fol. 79v), por el de La Clusa (dicho notario, 1497, fol. 53v) y por el término de Cabañas (dicho notario, 1496, fol. 73v).
} 


\section{El Romeral ${ }^{913}$}

- Simuel Abiayut y sus hijos Jaco y Juce: un albar que lindaba con majuelo de Domingo Betrián y con majuelo de Abraham Cohen.

- Jehuda Alpullat: una viña que lindaba con la de Gil Muñoz que, a su vez, lo hacía con Carrera de "Valluengo»; y un majuelo que lindaba con el del hospital de la villa que, a su vez, lo hacía con el de Lázaro del Campo.

- Abraham Cohen: un majuelo que lindaba con albar de Simuel Abiayut y de sus hijos Jaco y Juce Abiayut; y otro que lo hacía con el de Pero Serón, con La Carrera de Alpartir y con rasa de riego; este último lo heredó su hija Cinha.

- Hahim Cohen y su mujer Bellida de Sos: un majuelo que lindaba con el de Mosse Saltiel y con el de Juan de Clariana.

- Salamon Cohen: un majuelo que lindaba con el de Johanan Frances y con el de Esteban de Ruescas; una viña que lindaba con la del labrador Esteban de Ruescas que, a su vez, lo hacía con yermos; y otro majuelo que lindaba con viña del labrador Juan de Álvarez que, a su vez, lo hacía con majuelo de Domingo Tovar.

- Johanan Frances: un majuelo que lindaba con el de Pedro Sebastián, con el de Salamon Cohen y con el del castellano Juan Martínez del Río; otro que lindaba con el del labrador Pedro Pascual, alias de Alfocea, que, a su vez, lo hacía con el de Fernando del Pozo; y una viña que lindaba con la de Antón de Archant y con la «rasa del mullon".

- Benjamin Mocatil: un majuelo que lindaba con el de Martín Rasera 914 y con «el del conde».

- Acach Saltiel: una viña que lindaba con la de Acach Samarel, con albar de Acach Samarel también y con viña de la viuda de Pero Serón.

- Mosse Saltiel: un majuelo que lindaba con el de Hahim Cohen y de su mujer Bellida de Sos.

- Acach Samarel: una viña que lindaba con albar del labrador Antón de Salas que, a su vez, lo hacía con yermo de Martín López;

${ }^{913}$ Otras veces aparece este término como Carrera de Muelarroya o fincas que estaban en él se dan como sitas en dicha Carrera. Los "ortales» de Alpartir lindaban con "el açut del almunya de la cequia del Romeral» (dicho notario, 1496, fol. 23).

914 Martín tenía un campo «ius palacio», que lindaba con el de Pero Tejedor y con el de Miguel Gastón (dicho notario, 1484, fol. 14). 
un albar que lindaba con viña de Acach Saltiel, con una viña de Acach Samarel y con la de la viuda de Pero Serón; y un majuelo que lindaba con el del labrador Pedro Moreno y de su mujer María Martínez que, a su vez, lo hacía con el de Miguel Pellicero.

- Simuel Samarel: un majuelo que lindaba con el del labrador Pedro Moreno que, a su vez, lo hacía con el de Miguel Pellicero y con rasa de riego; y otro que lindaba con el del labrador Pedro Moreno y de su mujer María Martínez que, a su vez, lo hacía con el de Miguel Pellicero y con sendero; ambos podrían ser el mismo.

- Acach Xeteni: una viña que lindaba con la del labrador Juan Blasco y de su mujer Juana Muñoz que, a su vez, lo hacía con el majuelo de Juan Murero.

\section{El Sisallar}

- Semahon Carillo: una viña que lindaba con la de María de Bordalba que, a su vez, lo hacía con albar de Colás Marín.

\section{La Torrecilla}

- Juce Frances: una viña que lindaba con majuelo de la viuda Antona Escudero y de su hijo Miguel de Almudévar que, a su vez, lo hacía con viña de Antón de Salas y con campo de Jaime de Matas; y unos olivos que lindaban con majuelo de la viuda Antona Escudero que, a su vez, lo hacía con viña de Antón de Salas y con albar de Antón Catalán.

\section{La Vega de La Almunia}

- Simuel Samarel: un campo que lindaba con el de Bartolomé Serrano y con el de Miguel Contín, brazal en medio.

\section{La Vega del Hospital}

- Simuel Samarel: un campo que lindaba con el de Juan Navarro, de Almonacid, y con brazal de riego.

- Acach Xeteni: un campo que lindaba con el de Antón de Salas, con el de Domingo López y con brazal. 
Hubo también judíos que poseyeron campos en términos que no pertenecían a la villa de La Almunia, aunque estuvieran cerca de los de ésta:

Agra, término de Cabañas

- Jaco Albala: tierra blanca, que no se especificó.

- Juce Carillo: un campo que lindaba con el de Remón de Mur, con el de la capellanía de mosén Juan López y con brazal de riego.

- Juce Frances, mayor, y su nieto Juce Frances, menor: un campo que lindaba con el de la cofradía de Santa María y San Blas, con La Acequia de la Hermandad y con brazal.

Candenavas, término de Ricla

- Acach Abenforna: una viña que lindaba con la de Brahem Cuscullan, con la de Mahoma el Morisco y con «rasa del mullon».

\section{Castejón, término de Arándiga}

- Mosse Arruet: una viña tapiada, que lindaba con la de Juan Royo, con la de León Chopín y con carrera pública.

\section{La Huerta de Cabañas ${ }^{915}$}

- Jaco Albala: un campo sito allí, Carrera de Ricla, que lindaba con el del zapatero Pero de Luna, que tenía a treudo perpetuo de la cofradía de San Miguel y que lo hacía, a su vez, con el de Miguel de Longares.

\section{CONCLUSIONES *}

- Centrándome en los años a los que está dedicado este estudio -1470 a 1492 - y según la documentación, la comunidad judía

915 Podría ser término de La Almunia.

* La autora hace constar que el sangrado de algunas partes de documentos que van entrecomillados, se ha hecho según las normas de la revista. 
poseía sinagoga, cofradía, hospital, carnicería y cementerio - no se alude ni a horno ni a taberna ni a miqwé-, y haría uso de otras dependencias de la comunidad cristiana.

- Pese a mis muchos paseos por lo que pudo ser la judería de La Almunia, la delimitación precisa de ésta no es posible y mucho menos la identificación de edificios. Se sabe que la judería lindaba con el muro y con carreras públicas - posiblemente las actuales de San Juan, Rosario y Barrio Verde- por todas partes; pero dados los linderos de muchas casas de judíos con las de los cristianos, pienso que, en algunos sitios - la placeta de San Juan y Barrio Verde, por ejemplo-, sólo comprendería la parte interna de estos límites, aun teniendo en cuenta la profundidad de muchas casas de los judíos y sus, a veces, más de cuatro linderos. Lo que sí se sabe con seguridad es que la judería de la villa tenía una Plaza y dos carreras - posiblemente las hoy Barrio Curto, que comunica con Terrero, y Aceña - con dos cantonadas, donde era costumbre hacer las cridas.

- Los inmuebles de judíos documentados en la villa en estos años son: unas cuarenta y seis casas ${ }^{916}$, seis corrales y una tañería; y siete huertos, ocho campos, tres yermos, doce albares, de veintiocho a treinta majuelos y de cincuenta a cincuenta y dos viñas, además de los olivos de Juce Frances en La Torrecilla y la tierra blanca de Jaco Albala en Agra.

- Dado el número de casas y suponiendo que en cada una residieran, por término medio, unas cuatro o cinco personas, los habitantes de la judería de La Almunia durante estos años pueden estimarse, aproximadamente, en unos doscientos, aunque de ellos sólo se conozca el nombre de unos setenta y siete hombres, diecinueve mujeres y catorce jóvenes, incluidos los menores de edad ${ }^{917}$.

${ }^{916}$ Hay que tener en cuenta que no todas las casas que aparecen como propiedad de judíos, eran edificios enteros; podía tratarse de sólo parte de ellas, un ala, dos o tres habitaciones, o sólo una planta, siendo varias familias las que compartían un inmueble. La propiedad de las casas de los judíos fuera de la judería pudo muy bien estar motivada por la falta de pago de sus deudores: el caso de las de Johanan y Juce Frances, las posibles de Simuel Samarel, y las de Acach Xeteni y Jaco Albala. Todos ellos acostumbraron entregar préstamos y comandas.

917 Contando, claro está, no sólo a quienes comparecieron ante notarios cristianos, sino también a aquellas personas a las que se hace referencia o que actuaron como testigos instrumentales. 


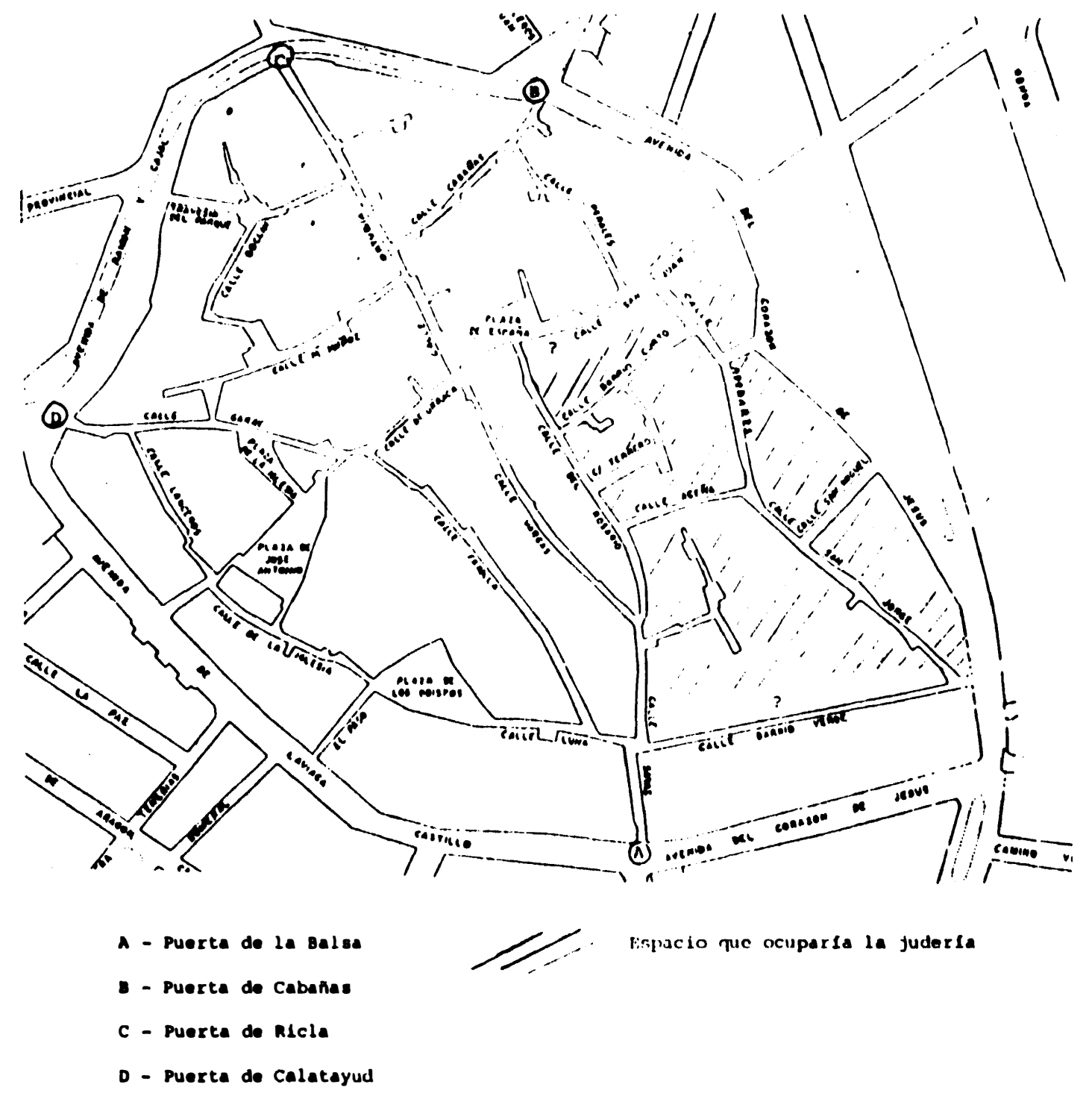

Plano de La Almunia de Doña Godina. 
- El precio de las casas, cuyo tamaño y orientación no los especificaba el notario, podía oscilar entre setenta, quinientos, setecientos y novecientos sueldos, incluso más; treinta se pagó por una parte de una tañería. El precio de las propiedades rústicas, cuyo tamaño y orientación tampoco especificaba el notario, variaba entre diez o doce sueldos, cien, doscientos, trescientos y mil sueldos.

- La documentación proporciona pocas referencias a ganado o animales de judíos -el carnicero Juce Carillo fue dueño de un asno de pelo pardo, otro tuvo Mosse Arruet-; por dos vacas se pagaron ciento veinte sueldos; quince florines de oro costaba un mulo y treinta un mulo y una mula en $1490{ }^{918}$.

- La administración y jurisdicción interna de la aljama estuvo a cargo de dos adelantados, luego tres, uno de los cuales desempeñaba las funciones de clavario; el samas hacía las veces de corredor $\mathrm{y}$ ante el notario judío se testificaban los instrumentos públicos.

- El empobrecimiento de la aljama - lo mismo que el de los concejos cristianos y aljamas moras - fue un hecho a partir de la segunda mitad del siglo XV e, incluso, antes, debido a los pagos de censos a los que tenía que hacer frente, en parte, y a las cargas impositivas que recaían sobre sus miembros. Este empobrecimiento no afectó, como se ha visto, a algunas familias.

- Puede decirse que los componentes de la comunidad judía casi se bastaban a sí mismos en cuanto a profesiones. Vivieron en ella tres rabíes ${ }^{919}$, tres médicos — nada se dice de cómo ejercieron su profesión-, un carnicero, un fustero, un pelaire, dos pellijeros, cinco tejedores, nueve sastres y un zapatero ${ }^{920}$. Frente a los muchos cristianos y moros que aparecen con el oficio de labradores, no recoge la documentación ni uno sólo que fuera judío; tampoco se

918 En 1480 un florín de oro equivalía a dieciséis sueldos.

919 Fue rabí de la villa en 1448 Jussuha Abenosiello.

920 Tres tuvo la comunidad cristiana. El 5 de junio de 1487, Francisco Martínez de Sanantón firmó a su hijo Juanico con el zapatero Pero Luna «al oficio de la çapateria", durante cuatro años a partir de entonces y con las siguientes condiciones: $1 .^{2}$, si el mozo se iba, Francisco debería "de yr andada de una jornada a buscarlo y traherlo" al servicio del zapatero; $2 .^{2}$, si el mozo se llevaba algo de su amo y se averiguaba que era así, tenía que pagarlo su padre; 3.", cada año Pero tenía que vestir y calzar al mozo "a su honor" y mantenerlo, sano y enfermo; y 4.", cumplidos los cuatro años, Pero tenía que vestir de nuevo al mozo y darle «todas sus manobras del officio de la çapateria». Ambas partes prometieron cumplir las condiciones estipuladas y obligaron sus bienes (L.A.APN., Miguel Contín, 1487, fol. 36v). 
nombra judío alguno que fuera mercader, quizá por la pérdida de protocolos.

- Pese a tener algunos judíos una profesión específica, la dedicación de muchos de ellos a entregar préstamos y comandas a los cristianos de su mismo lugar de residencia, y a éstos y a los moros que vivían en lugares cercanos a la villa, fue un hecho. Parece distinto el caso de Jaco Mocatil quien manifestó, después de su conversión, que

"teniendo desseo de tener oficio con que viva",

iba a aprender el de tejedor de betas, aunque según la única documentación encontrada anterior a 1492, no tuvo por costumbre dar comandas. Pocas veces los préstamos y comandas de los judíos de la villa consistieron en dinero ${ }^{921}$; sí en aceite, uvas, azafrán, trigo, ordio y cebada. En contadas ocasiones los judíos de la villa recibieron comandas de otros judíos ${ }^{922}$.

- La documentación aporta escasos datos sobre las relaciones existentes entre los miembros de la comunidad judía. Por lo que se refiere a las relaciones de los judíos de la villa con los cristianos, sólo constan cuando algún conflicto afectó a ambas comunidades, cuando existieron contactos de tipo económico o por compra o venta de inmuebles. Los judíos recurrirían a los cristianos que desempeñaban oficios de los que carecieran los componentes de la aljama. No se tiene constancia de conflicto alguno surgido por motivos religiosos entre ambas comunidades.

- Fue un hecho la influencia del fuero y observancia del reino en esta comunidad judía, como en todas las aragonesas. Aparece claro en el caso de nombramiento de tutores y curadores dativos,

${ }^{921}$ En la primera mitad del siglo XV lo dieron a los moros de Calatorao, a quienes los judíos de Zaragoza y Épila les proporcionaban grano. Parece como si los miembros de cada comunidad judía entregaran, en sus comandas y préstamos a los vecinos de un lugar, un determinado grano o producto.

${ }_{922}$ Los préstamos o entregas de dinero entre judíos solían consignarse ante los notarios judíos en forma de quinyan y juramento, carta pública de quinyan o contrato de quinyan (aparecen algunos casos en mi artículo En torno, 138-140, a veces otorgados entre judíos y cristianos). Los préstamos, comandas o censos, entregados por judíos o comprados por éstos a las aljamas, solían otorgarse, a veces, ante los notarios cristianos, ante quienes también se testificaron los respectivos albaranes de pago. 
aunque en el caso de los testamentarios se especificara, además, que se aplicaría la "ley e pratiqua de judios».

- Una vez conocido el edicto de expulsión, algunos judíos cobraron sus comandas con consentimiento expreso de los comisarios reales

«en el negocio de la spulssion de los judios de la villa",

Jaime de Matas y Martín Rasera, quienes recibieron las cantidades adeudadas, $y$ con

"voluntat, mandamiento y expresso consentimiento" o "con voluntat, decreto y actoridat"

de ambos, efectuaron ventas. A los comisarios se recurrió cuando se produjeron abusos contra los judíos o éstos los cometieron, pero en ocasiones los oficiales tardaron en tomar decisiones justas.

- No se sabe el número de judíos que pudieron salir de la villa de La Almunia. Aunque según la documentación lo hicieron con seguridad unos treinta y cinco, entre hombres, mujeres y niños, su número pudo ser mayor. Tampoco se sabe a dónde dirigieron sus primeros pasos, pues no les ocurrió como a los de Calatayud, que no podían ir a Zaragoza, donde

"havian fecho ordinacion et fecha crida que no pudiesse yr nenguno» de Calatayud a esta ciudad, a

«acoxer[se], por las muertes que ... [allí] ... andavan» ${ }^{923}$.

${ }^{923}$ Este fue el motivo de que, el 23 de julio de 1492 en La Almunia, ante el notario y los testigos, compareciera el médico Mosse Alazan, natural de Calatayud, pero «de present stant et resident» en dicha villa. Manifestó Mosse que él volvía a Zaragoza, donde "penssando que era de Calatayut no lo acoxerian", aunque él estuvo residiendo un mes seguido o más en Zaragoza, hasta el martes anterior, día 17, que partió de allí con su mujer y vinieron a La Almunia, donde permanecieron hasta entonces sin ir a Calatayud ni entrar en sus términos, ni salir de la villa. Para probar lo que manifestaba, Mosse trajo como testigos al trajinero bilbilitano Pedro Campos, al pellicero Alonso Pérez y al herrero Bartolomé Suñén, ambos de La Almunia. Después de que los tres testigos juraran sobre la cruz y los cuatro evangelios, ante el notario y a instancia de Mosse, decir la verdad, Pedro reconoció ser cierto lo manifestado por el médico judío, pues él los trajo de Zaragoza a La Almunia, "a la posada clamada de la viuda de Pero Seron"; por su parte, Alonso y Bartolomé reconocieron que el médico y su mujer llegaron el miércoles anterior, día 18, a dicha posada, donde estuvieron hasta entonces, lo que sabían porque ambos tenían sus casas junto a la posada (L.A.APN., Miguel Contín, 1492, fols. 85-85v). Con el acta que le entregara el notario de la testificación de los tres testigos, Mosse y su mujer volverían a Zaragoza con la esperanza de que se les acogiera. Recuérdese el parentesco de este matrimonio con los judíos Frances, de La Almunia. 
- Tras la expulsión de los judíos, el importe de las comandas y deudos, que se les debían, pasaron a pertenecer a don Juan de Aragón, conde de Ribagorza y señor de la judería de La Almunia,

"en quien ha venido la present comanda", porque "le cayo en parte en los deudos de los jodios»

o porque tenía derecho a ella

"por el recesso de su vasallo...".

El conde don Juan nombró procurador suyo al caballero mosén Juan Ximeno, que en abril de 1492 era baile de los judíos de la villa ${ }^{924}$. Mosén Juan, a su vez, nombró procurador para que lo sustituyera, como procurador del conde de Ribagorza, al citado Jaime de Matas, justicia de la villa, quien fue cobrando y cancelando comandas y deudos, en nombre del conde, desde 1492 hasta 1497, por lo menos ${ }^{925}$.

- Después de la expulsión de los judíos, algunos censalistas de la aljama recibieron bienes inmuebles de judíos o comandas debidas a éstos a cambio de los censos; otras veces fueron los comisarios reales de la expulsión, Jaime de Matas y Martín Rasera, quienes efectuaron ventas de bienes de judíos para pagar los censales que debía la aljama.

- Aunque fue intención real

"que nenguno en su justicia con descepciones no sea vexado ni molestado",

no siempre ocurrió así. Creo que debe resaltarse la decisión de justicia del rey don Fernando, una vez expulsados los judíos del reino, y cómo ésta llegó a La Almunia, cuando una viuda y su hija doncella apelaron a él, después de haber pasado por un justicia que resolvió, por la corte del justicia de Aragón que adjudicó y por un árbitro y amigable componedor que emitió sentencia, sin que ninguna de estas resoluciones hubieran servido para obtener la devolución de

${ }^{924}$ El 11 de octubre de 1492 en Zaragoza, el conde de Ribagorza nombró también procurador suyo al antiguo tesorero de su padre, Lorenzo de la Caballería, quien actuó como tal el 25 de dicho mes y año.

${ }_{925}$ El escudero del comendador de la villa, al cancelar en 1493 una comanda debida a Johanan Frances, lo hizo con el consentimiento del justicia y comisario de la expulsión, y procurador del conde de Ribagorza. 
unos bienes que les sustrajeron con actos falsos tres judíos que habían sido vecinos de la villa.

- Por lo que se refiere a los conversos, se sabe que lo fueron Juan Muebla, que fue procurador de Bernardo de la Caballería; Martín de la Plana, hermano de la mujer del judío Alazar Ferrer; y es posible que lo fueran Juan de Sanantón, que en el año 1444 prestó mucho, y el especiero Bernardo de Santángel, aunque la documentación no lo señala nunca, tal vez por su parentesco por matrimonio con la familia de los escuderos Matas ${ }^{926}$.

En la segunda parte de este estudio dije que en los procesos inquisitoriales de conversos judaizantes aragoneses que se conservan en el Archivo de la Audiencia de Zaragoza, el total de los cuales he estudiado, no aparece proceso alguno de conversos de La Almunia. Sin embargo, el proceso del cedacero Juan Ferrer, de Zaragoza, contiene las abjuraciones de tres conversos de la villa o que residieron temporalmente en ella: la citada María de Funes, que vivió en el lugar de Calatorao y, después de su matrimonio, en la villa ${ }^{927}$, su

${ }^{926}$ El 21 de diciembre de 1482, el especiero Bernardo de Santángel nombró procurador general a pleitos, sin revocar los que tuviera, a su cuñado Miguel de Matas, para demandar, recibir y cobrar cualquier cantidad o cosa que le debieran su difunto vecino Juan de Ejea y su hijo Miguel, éste de Zaragoza y como heredero de su padre, "de medecinas et otras cosas tomadas de mi botigua en su enfermedat y de los de su casa»; y para otorgar albaranes, si cobraba (L.A.APN., Miguel Contín, 1482, fol. 15). Un año largo después, concretamente el 29 de marzo de 1484, Juan de la Gorda, de Ricla, firmó a su hijo Juanico de Luna con Bernardo de Santángel «al arte de speciero, si quiere specieria", durante seis años y medio a partir de entonces y con las siguientes condiciones: 1.", Bernardo tenía que enseñarle a leer y escribir, si quería aprender, y a trabajar "por vuestro poder, que lo sepia et demostrarle el arte de la specieria»; 2.", Bernardo tenía que llevarlo bien vestido y calzado, "honradamente a vuestra honra»; 3.", Juan de la Gorda no podía quitarle el aprendiz durante dicho tiempo, ni éste irse del servicio y casa del especiero; si se iba, el padre debería "tornarlo al servicio"; $4 .^{2}$, si el mozo se llevaba algo de la casa y botiga de Bernardo y se demostraba, el padre tenía que pagarlo y reincorporar a su hijo al servicio; y 5.^, Bernardo debería mantener al mozo, sano y enfermo, y con las condiciones dichas. Juan firmó a su hijo con el especiero, Bernardo lo tomó a su servicio y ambas partes prometieron cumplir y obligaron sus personas y bienes (dicho notario, 1484, fols. $12 v-13)$. El 6 de noviembre de este mismo año, Bernardo compró a su cuñado, el escudero Juan de Matas, un olivar, libre de cargas y sito en los olivares de El Brazal de La Noguera, por ciento quince sueldos (dicho notario y año, fols. 51v-52 y 67 67v).

927 María de Funes abjuró: de haber ayunado el quipur en dicho lugar; de comer pan cotazo, "arruquaques y turrado» en la pascua judía, que le enviaban judíos de la villa, carne degollada por judío, con su ceremonia, sin necesidad, hamin en sábado, guisado el viernes, y otros días de la semana, que le enviaban también los judíos de 
marido el tejedor Jaime de Luna ${ }^{928}$ e Isabel Salvador, viuda de Pero López ${ }^{929}$, ambos residentes en La Almunia. Estas abjuraciones que, como todas, son generales y que tuvieron lugar el 24 de enero de 1489 , desgraciadamente no añaden nada nuevo sobre la comunidad judía de la villa y sus componentes en particular - se nombra a un Albala, pero sin especificar su nombre. Sólo se sabe que Isabel se hizo cristiana antes de 1469 , pero no constan los nombres y apellidos judíos de estos tres conversos ni su parentesco con las familias judías de la villa. Aún así, las tres abjuraciones ponen de manifiesto:

1) La actividad de las mujeres judías de la villa los viernes para surtir el sábado de hamin a las familias conversas que se lo pedían. Hamin que saldría de la judería llevado por unos u otros o por los mozos de servir, del mismo modo que los potajes y guisos preparados por ellas. No se sabe si, como en otros muchos lugares aragoneses, eran los propios conversos los que el jueves o viernes por la mañana enviaban a las casas de sus parientes o amigos judíos los garbanzos, la carne y los huevos para prepararlo, o dinero.

2) La cantidad de pan cotazo o cenceño que había de prepararse en la judería antes de la pascua para abastecer de el y de "arruquaques y turrado" a las casas de los conversos que lo solicitaban,

la villa; de no trabajar el sábado por devoción al sabat; de comer en las bodas de Albala viandas y vino judío y estar en ellas un día sirviendo; de comer carne en cuaresma estando sana; de beber vino judaico; de entrar en cabañuelas de judíos, hacer colación en ellas y beber vino; de visitar a una judía enferma; y de no saber el credo (Z.AAT., leg. 34, $\mathrm{n}^{2}$ 2, fols. 16-16v).

928 Jaime abjuró: de ayunar el quipur, llamado «ayuno del perdon»; de guardar el sabat algunas veces; de trabajar en domingos y días de guardar por la iglesia; de comer cotazo, "turrado" y "arruquaques» en la pascua judía; de comer carne en viernes y en cuaresma, estando sano; de comer en bodas de judíos de sus viandas; de no comer tocino ni gordura ninguna; de comer hamin en sábado, hecho el viernes con carne de la judería; de estar en cabañuelas de judios y comer en ellas; de decir algunas veces con "malenconia" que le pesaba haberse hecho cristiano y haberse vuelto de la buena ley de los judíos a la mala de los cristianos; de decir que también se podía salvar el buen judío en su ley, como el buen cristiano en la suya; de no haber aprendido el credo; y de haber entrado, siendo cristiano, un día en la sinagoga quitado el bonete, $y$ hacer "humildat a la tora" (dicho leg. y $\mathrm{n}^{2}$, fols. 17v-18).

929 Isabel adjuró: de no hilar el sábado; de comer pan cotazo, «arruquaques y turrado" en la pascua judía; de enviar "en retribucion» al terminar ésta a quienes se lo mandaban, pan leudo y lechugas; de que, aconsejada por alguien antes de 1469, ayunó el quipur; de comer potajes y comeres guisados por judíos y carne de la carnicería de éstos, degollada con ceremonia judaica; y de comer hamin hecho con garbanzos, que ella sabía guisar bien (dicho leg. y $\mathrm{n}^{2}$, fols. 17-17v). 
quienes "de retorno", como en tantos otros lugares, solían enviar pan leudo y lechugas. ¿Les proporcionaban los conversos la harina, como acostumbraron hacer en otros sitios?

3) Los animales que se necesitaba degollar en la judería para atender, no sólo las necesidades de la comunidad judía, sino también las de los conversos. ¿Eran los propios judíos quienes, a petición de éstos, compraban la carne o eran los conversos quienes acudían a recogerla a la carnicería de la judería o a las casas de sus parientes o amigos judíos?

4) La llegada de los conversos a la judería cuando se montaban las cabañuelas, su estancia en ellas, donde comían y bebían con sus dueños judíos y jugaban a «tablas», a «crescas», etc.

5) Cómo criticarían los cristianos: la escasa actividad o total inactividad de los conversos que celebraban y observaban el sabat, en contraste con los trabajos que hacían los domingos y fiestas cristianas; el consumo de carne en viernes y cuaresma en algunas casas de conversos; el recogimiento de muchos de éstos el día del quipur o ayuno del perdón, y sus paseos por la villa o los campos con pálidos semblantes; $y$, sobre todo, las idas de los conversos a la judería con el pretexto de asistir a bodas, de visitar a enfermos judíos, etc., y, lo que no sabían, para aprovechar y acudir a la sinagoga, en ocasiones.

Entre los conversos de los que conocemos su nombre o apellido judíos y que se convirtieron después de conocerse el edicto de expulsión, se encuentran: Adam de Ortubia, antes Salamon Abendada, y María de Ortubia, posible hija suya; Ochona de Archant, antes Jehuda Almalcani, y Antón de Archant, su hermano; y Pedro Longares, antes Jaco Mocatil; también se convirtió Simuel Pardo, pero no se sabe su nombre cristiano. Dado el número de judíos que parece residieron en la villa, fueron pocos los documentados que optaron por el bautismo y permanencia en ella, porque nada se sabe de todos los demás judíos que no aparecen en los instrumentos públicos notariales.

Cuando se termina un trabajo hay muchos datos que al estudioso le gustaría conocer y que la documentación no le proporciona: 
desenvolvimiento interno de la aljama, aspectos sociales, intelectuales y religiosos; vida diaria, parentescos, relaciones, preocupaciones, pensamientos e ideas de sus componentes. No he tenido la suerte de encontrar ni un sólo testamento, aunque sí alusiones - lo que induce a pensar que no los hacían con frecuencia-, que son tan reveladores en éstas y otras cuestiones. En el caso de La Almunia pienso que los protocolos perdidos, o que no se encuentran en su archivo, de notarios a los que se alude, hubieran podido dar respuesta a muchas de estas preguntas.

Espero en sucesivas investigaciones completar el conocimiento sobre esta aljama y sus moradores y responder a algunos de los interrogantes que tras la lectura de este trabajo han podido suscitarse.

\section{RESUMEN}

Este estudio está dedicado a los judíos que residieron en La Almunia de Doña Godina, villa aragonesa de señorío, desde 1470 a 1492. A través de él se intenta reflejar la realidad que los documentos muestran sobre la vida de los judíos de esta villa, en los siguientes apartados: judería: sinagoga, hospital, cementerio, carnicería y otras dependencias; aljama: administración, adelantados y clavarios, impuestos, y censos y comandas debidos por la aljama; préstamos y comandas debidos a judíos; relaciones entre judíos y con la comunidad cristiana; familias judías de la villa; términos de la villa donde los judíos tenían propiedades inmuebles; y conclusiones. $\mathrm{Su}$ base documental son los instrumentos públicos notariales que se conservan en los Archivos de Protocolos Notariales de La Almunia de Doña Godina, especialmente, y de Zaragoza y Calatayud.

\section{SUMMARY}

The present study is devoted to the Jews who lived in La Almunia de Doña Godina, an Aragonese village of noble rank, from 1470 to 1492 , in an attempt to present the reality of their everyday life, as shown in the available documents: the Jewish quarter: synagogue, hospital, graveyard, butchery and other city offices; the aljama: administration, adelantados and clavarios, taxes, préstamos and comandas either due to or payable by the community or particulars; inner relations between the Jews and with the Christian community; Jewish families of the village; city boundaries within which they owned estate properties; and conclusions. The documentary evidence on which the current study is based are the notary deeds that are kept in the Archives of Protocolos Notariales of La Almunia de Dona Godina, particularly, and of Zaragoza and Calatayud, too. 